\title{
STRATEGI PEMASARAN PAKET WISATA PADA PT. PANDAWA LIMA TOUR AND TRAVEL INDONESIA DI DENPASAR
}

\author{
I Gede Adhi Suputra Arimbawa PG \\ I GPB. Sasrawan Mananda \\ I Putu Sudana \\ Email : pg.dueg@yahoo.com \\ PS. S1 Industri Perjalanan Wisata \\ Fakultas Pariwisata UNUD
}

\begin{abstract}
This research is about the marketing strategies implemented by PT. Pandawa Lima Tour and Travel tour packages. Company offers tour packages in Bali and beyond Bali tour packages with variety of facilities. As a common general company, PT. Pandawa Lima Tour and Travel has the objective to make profit and trying to satisfy consumers. This research aims to determine the marketing strategy package in PT. Pandawa Lima Tour and Travel tour package in Denpasar. The data collection method in research carried out by the method of observation, in-depth interviews, library research, and technique documentation. The data analysis technique used is descriptive qualitative combined with the SWOT approach.

Discussion of the results of the marketing strategy adopted by the PT. Pandawa Lima Tour and Travel is SO strategy by increasing sales promotion to target markets, enhance cooperation with hotels and travel agents and maintain the diversity and innovation of product and service quality. ST strategies to further enhance cooperation with other travel agencies, and improve service quality. WO strategies to enhance the promotion through the mass media, and printing brochures, expanding market segments and improve the quality of human resources in education and training. While WT strategy by increasing promotional activities and improve human resources. Based on the results of the discussion, can give advice - advice on marketing strategies in PT. Pandawa Lima Tour and Travel tour packages that maintain good relations with the company's existing transport and suggest PT. Pandawa Lima Tour and Travel to their own transport, improving education and training for employees and appropriate compensation, as well as updating the architecture buildings and office equipment.
\end{abstract}

Keywords: Marketing Strategy, Package Tour.

\section{PENDAHULUAN}

Perkembangan Biro Perjalanan Wisata di Bali setiap tahu selalu mengalami peningkatan, sehingga terjadi persaingan yang ketat antar penyedia jasa perjalanan wisata. Salah satu dari sekian banyak biro perjalanan wisata yang ada di Bali adalah PT. Pandawa Lima Tours and Travel yang beralamat di Jln. Gelogor Carik 154 Denpasar. Produk-produk Pandawa Lima Tours and Travel ini diantaranya: paket wisata Pandawa Lima Tours and Travel, paket wisata milik biro perjalanan wisata lain yang dijual oleh Pandawa Lima Tours and Travel, paket yang terdiri dari beberapa Tours, dan paket wisata luar Bali.

Melihat perkembangan Pandawa Lima Tours and Travel dan banyaknya biro perjalanan wisata di Bali dengan tingkat persaingan yang tinggi, maka untuk bisa memenangkan persaingan tersebut diperlukan suatu strategi pemasaran dan penerapan teknologi untuk mendukung usahanya. Sehingga dirasakan sangat perlu melakukan sebuah penelitian yang membahas tentang strategi pemasaran yang diterapkan oleh Pandawa Lima Tours and Travel untuk menjaga keberadaanya dalam dunia persaingan 
pasar usaha perjalanan dalam rangka meningkatkan jumlah penjualan paket wisata.

\section{TINJAUAN PUSTAKA}

Menurut Krippendorf (dalam Yoeti, 2002:1) merumuskan pemasaran pariwisata sebagai berikut: "Suatu sistem yang dibuat oleh sebuah perusahaan pariwisata baik swasta atau pemerintah yang tujuannya adalah untuk mencapai kepuasan wisatawan dan pada akhirnya dapat memperoleh keuntungan".

Menurut Kotler (1994:41) mendefinisikan "marketing mix sebagai serangkaian variable pemasaran terkendali yang dipakai oleh perusahaan untuk mengahasilkan tanggapan yang dikehendaki perusahaan dari pasar sasarannnya".

Menurut IUTO (Internasional Union of Official Travel Organization) memberikan ulasan bahwa: "Wisatawan merupakan pengunjung sementara yang tinggal di suatu objek wisata dan menghabiskan waktunya untuk bersenang-senang dan tinggal minimal 24 jam di negara atau objek wisata yang dikunjunginya"

Menurut

Damardjati

(1995:5)

memberikan batasan tentang travel agent sebagai berikut. "Travel Agent adalah sebuah usaha jasa yang mempunyai fungsi untuk merencanakan dan mejalankan sebuah paket wisata termasuk didalamnya kelengkapan perjalanan wisata seperti transportasi, guide, dan yang lainnya dari baik di dalam maupun luar negeri".

Darmadjati (dalam Suyitno, $2001: 67$ ) mengartikan paket wisata sebagai suatu rencana kegiatan pariwisata yang disusun secara sigtematis, rapi dan terstruktur dengan harga tertentu dan didalamnya termasuk pula biaya-biaya seperti transfer, fasilitas akomodasi/hotel, objek wisata dan atraksi yang termasuk di dalam paket wisata tersebut.

\section{METODE PENELITIAN}

Penelitian ini dilaksanakan di PT. Pandawa Lima Tour and Travel yang merupakan salah satu perusahaan biro perjalanan wisata yang berlokasi di Jln. Gelogor Carik 154 Denpasar Bali. Adapun alasan memilih lokasi ini karena PT. Pandawa Lima Tour and Travel merupakan sebuah biro perjalanan wisata yang berbeda dengan biro perjalanan wisata lainnya. Perbedaan tersebut tampak dari segmentasi pasar yang dipilihnya yaitu memprioritaskan wisatawan mancanegara. Selain itu, dalam melaksanakan fungsinya sebagai sebuah biro perjalanan wisata, PT. Pandawa Lima Tour and Travel bekerja sama dengan agen perjalanan luar negeri.

\section{HASIL DAN PEMBAHASAN Strategi SO}

1. Strategi yang memanfaatkan kekuatan atas peluang yang telah diidentifikasi. Strategi yang dapat diterapkan dalam memasarkan PT. Pandawa Tour and Travel adalah strategi penciptaan dan pengembangan produk Wisata.

2. Memaksimalkan pemasaran yang dilakukan dengan menawarkan produk wisata yang dimiliki oleh PT. Pandawa Tour and Travel dengan baik,

3. Menjaga dan membina hubungan kerjasama yang lebih baik dengan relasi yang terkait dalam bidang industri pariwisata seperti hotel, restoran, dan transportasi.

\section{Strategi ST}

1. Meningkatkan dan mempertahankan kerjasama dengan biro perjalanan wisata yang telah terbina dengan baik, untuk biro perjalanan wisata yang ada di Bali maupun yang ada di luar negeri.

2. Mempertahankan harga yang pantas sesuai dengan keinginan konsumen dan kualitas produk untuk memenangkan persaingan.

3. Meningkatkan kualitas pelayanan dengan memberikan good quality service kepada konsumen, karena pada dasarnya kepuasan pelanggan merupakan hal yang utama dalam usaha jasa pariwisata.

\section{Strategi WO}

1. Strategi yang meminimalkan kelemahan dengan berusaha memanfaatkan peluang yang ada. Strategi yang dapat diterapkan dalam memasarkan PT. Panorama Tours and Travel adalah strategi peningkatan promosi dan strategi peningkatan sumber daya manusia.

2. Menjaga hubungan baik dengan beberapa perusahaan transportasi yang ada. Selain itu mengadakan pembaharuan terhadap alat-alat kantor yang rusak.

3. Meningkatkan kinerja dan kualitas karyawan untuk meningkatkan pelayanan kepada wisatawan dengan meningkatkan minat wisatawan tehadap produk dan karyawan juga 
mampu memanfaatkan media komunikasi yang ada.

4. Meningkatkan mutu pelayanan pada wisatawan untuk peningkatan kepuasan wisatawan, kususnya yang dikirim oleh agent asing agar tidak terjadi keterlambatan pembayaran.

\section{Strategi WT}

1. Menjamin mutu produk dan pelayanan

2. Memperluas segmen pasar dan meningkatkan promosi dengan pencetakan brosur dan lainnya untuk bisa memenangkan persaingan dengan biro perjalanan lain di Bali.

3. Peningkatan kualitas sumber daya manusia melalui pelatihan terutama bagi karyawan baru untuk bisa memberikan pelayanan yang lebih baik dalam menghadapi pelanggan yang lebih selektif di dalam memilih produk wisata dan mampu memberikan pengetahuan dan pemahaman kepada konsumen yang akan menggunakan produk paket wisata yang dibuat.

\section{KESIMPULAN DAN SARAN Simpulan}

Berdasarkan pembahasan strategi pemasaran paket wisata PT. Pandawa Lima Tour and Travel, yang menggunakan metode analisis SWOT yang menganalisis mengenai Strenghs (kekuatan), Weaknesses (kelemahan), Opportunities (peluang), dan Threats (ancaman) terhadap unsur-unsur marketing mix pada pemasaran paket wisata PT. Pandawa Lima Tour and Travel, maka dapat diambil kesimpulan sesuai hasil analisis SWOT strategi pemasaran yang diterapkan yaitu:

1. Produk

Strategi produk yang harus diterapkan oleh PT. Pandawa Lima Tours and Travel adalah meningkatkan dan mengembangkan produk yang diminati wisatawan dan peningkatan pelayanan agar dapat memenangkan persaingan dengan biro perjalanan wisata maupun travel agent lainnya yang menawarkan produk sejenis.

2. Harga

Berdasarkan penjelasan dari pihak manajemen, tarif acuan tersebut memang ditetapkan cukup tinggi dengan pertimbangan bahwa penetapan harga dari suatu produk memberikan persepsi tersendiri atas kualitas dari produk tersebut. Harga tersebut selalu disisuaikan dengan kondisi pasar sebagai acuan, penetapan harga akhir mempertimbangkan jumlah wisatawan dalam suatu periode disamping juga pertimbangan lainnya.

3. Saluran Distribusi

Sistem distribusi yang dilakukan oleh PT. Pandawa Lima Tour and Travel banyak mengandalkan sektor informal yaitu dengan mengadakan perjanjian tertulis terhadap komponen pariwisata, seperti para pramuwisata, pegawai hotel, restoran dan sebagainya. Sektor formalnya adalah mengadakan kerjasama dengan biro perjalanan lainnya baik yang berada di luar maupun di luar negeri.

4. Promosi

Dalam mempromosikan produknyaproduknya, PT. Pandawa Lima Tour and Travel melakukan suatu reisen sommer (sales promotion) yang dilakukan oleh Manager Direktur (pemilik perusahaan) ke overseas agent.

5. Personal

Personal yang dimaksud disini adalah seseorang yang terlibat dalam pelayanan kepada wisatawan baik secara langsung maupun tidak langsung yang menggunakan jasa pelayanan PT. Pandawa Lima Tour and Travel.

6. Bukti Fisik

PT. Pandawa Lima Tours and Travel mempunyai sarana pendukung bukti fisik seperti yang termasuk di dalamnya adalah seragam karyawan, sarana transportasi, dan bangunan.

7. Proses

Sebagai sebuah biro perjalanan wisata, PT. Pandawa Lima Tour and Travel memiliki proses sales and marketing dalam memasarkan produk-produknya. Adapun proses tersebut dapat dijelaskan sebagai berikut. Bagian sales and marketing dari PT. Pandawa Lima Tour and Travel melakukan reisen sommer atau yang lebih dikenal dengan istilah sales promotion.

\section{Saran}

Saran yang dapat diberikan kepada PT. Pandawa Lima Tour and Travel dalam rangka supaya dapat meningkatkan kualitas pelayanan kepada wisatawan adalah sebagai berikut:

1. Membina hubungan yang baik dengan perusahaan yang terkait dalam penjualan paket wisata PT. Pandawa Lima Tour and 
Travel seperti pihak hotel, restoran, dan juga transportasi.

2. Arsitektur bangunan PT. Pandawa Lima Tours and Travel perlu diperbaharui supaya pihak-pihak yang sedang menyelesaikan urusannya dengan PT. Pandawa Lima Tours and Travel merasa nyaman. Selain itu, peralatan kerja di kantor PT. Pandawa Lima Tours and Travel perlu diperbaharui untuk meningkatkan kelancaran dalam melakukan pekerjaan. Karena ada sebagian kecilperalatan kantor yang rusak dan mungkin sudah waktunya untuk diganti dengan baru.

3. Kualitas pelayanan yang selama ini hendaknya dijaga dan ditingkatkan agar wisatawan puas sehingga hubungan antara PT. Pandawa Lima Tours and Travel dengan Overseas Agents akan selalu terbina dengan baik.

\section{DAFTAR PUSTAKA}

Damardjati, R.S. 1995. Istilah - Istilah Dunia Pariwisata. Jakarta: Pradnya Paramita.

Kotler, Philip. 1994a. Marketing. Phineche INc, England. . 1994b. Pemasaran Pariwisata. Phineche Inc, England.

Rangkuti, F. 2001. Analisis SWOT Teknik Membedah Kasus Bisnis, PT. Gramedia Pustaka Utama, Jakarta.

Yoeti, Oka A. 1993. Pengantar Pariwisata. Jakarta: Angkasa. 1996. Pemasaran Pariwisata. Bandung: Angkasa: Bandung.

Yoeti, O.A.2001.Tours and Travel Management.Jakarta: PT. Pradnyana Paramita. 